\title{
Photobiomodulation using high- or low-level laser irradiations in patients with lumbar disc degenerative changes: disappointing outcomes and remarks
}

This article was published in the following Dove Press journal:

Clinical Interventions in Aging

\section{Jakub Taradaj ${ }^{1,2}$ \\ Katarzyna Rajfur ${ }^{3}$ \\ Barbara Shay ${ }^{2}$ \\ Joanna Rajfur ${ }^{3}$ \\ Kuba Ptaszkowski ${ }^{4}$ \\ Karolina Walewicz ${ }^{3}$ \\ Robert Dymarek ${ }^{5}$ \\ Mirosław Sopel ${ }^{5}$ \\ Joanna Rosińczuk ${ }^{5}$}

'Department of Physiotherapy Basics, Academy of Physical Education,

Katowice, Poland; ${ }^{2}$ College of Rehabilitation Sciences, University of Manitoba, Winnipeg, MB, Canada; ${ }^{3}$ Public Higher Medical Professional School, Opole, Poland; ${ }^{4}$ Department of Clinical Biomechanics and Physiotherapy in Motor System Disorders, Wroclaw Medical University, Wroclaw, Poland; ${ }^{5}$ Department of Nervous System Diseases, Wroclaw Medical University, Wroclaw, Poland
Correspondence: Robert Dymarek Department of Nervous System Diseases, Wroclaw Medical University, 5 Bartla Street, 5I-618 Wroclaw, Poland $\mathrm{Tel}+48$ 7। 784 I8 05

Fax +48 7I 34I 9533

Email r.dymarek@gmail.com
Background: Laser therapy seems to be a beneficial physical agent for chronic low back pain (LBP), and it is commonly used in the clinical rehabilitation practice. However, there are still no indisputable and clearly defined protocols and practical guidelines, and further, the methodology of the previous reports leaves many unsatisfied and raises some reservations.

Objective: The aim of this study was to evaluate the effectiveness of low-level laser therapy (LLLT) and high-intensity laser therapy (HILT) in patients with lumbar disc degenerative changes based on the analysis of the short- and long-term results and in comparison with the placebo effect.

Design: This study was a prospective and placebo-controlled clinical trial.

Materials and methods: A group of 68 participants were qualified for the therapy and were assigned to four comparative groups in the order they volunteered: HILT of $1,064 \mathrm{~nm}, 60 \mathrm{~J} / \mathrm{cm}^{2}$, 10 minutes (HILT); sham (HILT placebo); LLLT of $785 \mathrm{~nm}, 8 \mathrm{~J} / \mathrm{cm}^{2}, 8$ minutes; and sham (LLLT placebo). The following tests were used to assess the effectiveness of treatment: 1) the visual analogue scale; 2) the Laitinen Questionnaire Indicators of Pain; 3) the Oswestry Disability Index; 4) the Roland-Morris Disability Questionnaire; 5) Lasegue test; and 6) Schober's test. All measurements were carried out before and after irradiations (3 weeks) and in follow-ups (1 and 3 months).

Results: After applying verum or placebo laser irradiation, therapeutic progress was observed in all comparative groups; however, no statistically significant differences were observed among the procedures.

Conclusion: The high- and low-energy laser therapy methods used in the present article are ineffective in relation to patients with lumbar disc degenerative changes in both the short- and long-term perspectives and do not show a significant advantage over the placebo effect.

Keywords: laser therapy, low back pain, lumbar disc degenerative changes, photobiomodulation therapy

\section{Introduction}

Numerous reports based on basic research - mainly in vitro studies ${ }^{1,2}$ and animal experiments $^{3-5}$ - form the basis for claiming that laser therapy can have a beneficial effect on musculoskeletal disorders. In addition, scientists in their clinical trials have repeatedly demonstrated positive anti-inflammatory and analgesic effects in selected disease aspects in both objective terms with the use of modern laboratory equipment eg, pathomorphological or immunocytochemical analysis of isolated tissues ${ }^{6,7}-$ and 
subjective terms, based on the feelings of study participants regarding the symptoms of local inflammation or pain reduction. ${ }^{8-10}$

However, when making a critical review of the literature, ${ }^{11,12}$ one cannot overlook the fact that further wellplanned clinical trials should be continued to fully verify the utility of therapeutic laser irradiation, because, despite the considerable interest of the scientific community, there are still no indisputable and clearly defined protocols and practical guidelines, and further, the methodology of the previous reports leaves many unsatisfied and raises some reservations.

A similar problem exists when using high- and lowenergy radiation in patients with lumbar disc degenerative disease. ${ }^{13,14}$ So far, no worldwide research has been carried out in which photobiomodulation therapies using low-level laser therapy (LLLT) and high-intensity laser therapy (HILT) have been compared under one research protocol in relation to this subject. In addition, in the previous articles, most of the control groups were not provided in the study design (especially using placebo or sham procedures), and a detailed protocol with homogenous inclusion and exclusion criteria and the narrow-gauge observations were conducted based on only one or several monothematic scales or questionnaires. There appears to be a lack of outreach activities in which the authors would undertake a comprehensive assessment of the suitability of laser therapy. Long-term results were not often completed to verify whether the achieved therapeutic effects were short-term or whether the remission of disease symptoms persisted for a longer period of time from the end of treatment sessions.

The aim of this study was to evaluate the effectiveness of LLLT and HILT in patients with lumbar disc degenerative changes based on the analysis of the short- and long-term results and in comparison with the placebo effect.

\section{Materials and methods}

\section{Ethical considerations}

The research project was approved by the Independent Bioethics Committee of Wroclaw Medical University (No KB-666/2015). The study was conducted in accordance with the guidelines of the Declaration of Helsinki and the principles of Good Clinical Practice, as well as in respect for the rights and dignity of the other person. All the participants singed and provided written informed consent after thorough explanation of the procedures involved. The study included adult participants with chronic discogenic low back pain (LBP) who were referred for treatment to the Laboratory of Functional Studies at the Faculty of Physiotherapy of Higher Medical Professional School in Opole, Poland. The interpretation and analysis of the results and paper-preparing process were taken place at the College of Rehabilitation Sciences in Winnipeg, MB, Canada.

\section{Inclusion and exclusion criteria}

Participants with lumbar disc degenerative dysfunction, chronic pain deficits, or pseudoradicular pain syndrome who had never undergone any surgical intervention in the spine were included in the study. The participants had current results of MRI examination, which confirmed the precise diagnosis of the disease with visible radiological changes in the intervertebral discs at the L5-S1 segment of the spine (as the inclusion criterion, pathological changes of at least a third grade were accepted according to the Modic classification system). The participants with initial pathology in another segment of the spine (only first grade or at most a second grade) were also included. In addition, those with lumbar disc degenerative dysfunction and cancer history of at least 1 year after the end of treatment were included, and no relapse or metastasis was not the reason for exclusion from further recruitment.

Participants with any acute pain symptoms during the half-year period until the start of the study were excluded from this project. Those with a radicular syndrome or, in the case of the intervertebral discs, pathology in another segment of the spine were also not eligible. The exclusion criteria also included other dysfunctions of the spine (ie, fractures, tumors, spondylolisthesis, rheumatic diseases, and cauda equina syndrome). Pregnant women and participants who had cardiovascular failure, a pacemaker, metal implants, skin lesions in the treatment area, sensory disturbances, or psychosomatic disorders were also excluded. Those who had a diagnosis of active cancer or a cancer history of $<1$ year after the end of treatment; psoriasis; scleroderma; and viral, fungal, and bacterial infections were also excluded. In addition, those taking any analgesics or anti-inflammatory drugs were not allowed to participate in the study.

\section{Patients' characteristics}

Finally, a group of 68 participants were qualified for the therapy and were assigned to four comparative groups in the order they volunteered. All groups were homogeneous in terms of basic demographic characteristics and other factors that could affect results, such age, height, body weight, and duration of disease. Table 1 shows the detailed analysis of participant homogeneity. The study groups were also 
Table I Demographic characteristics of participants in the study

\begin{tabular}{|c|c|c|c|c|c|c|c|c|c|c|}
\hline Characteristics & Group & $\mathbf{n}$ & $\overline{\mathbf{X}}$ & Me & Min & Max & Q25 & Q75 & SD & $\begin{array}{l}\text { P-value (Kruskal-Wallis } \\
\text { ANOVA) }\end{array}$ \\
\hline \multirow[t]{4}{*}{ Age (years) } & HILT & 18 & 44.67 & 44.00 & 29.00 & 58.00 & 41.00 & 48.00 & 4.96 & 0.8436 \\
\hline & HILT (p) & 17 & 44.24 & 45.00 & 26.00 & 51.00 & 41.00 & 47.00 & 4.34 & \\
\hline & LLLT & 16 & 45.19 & 45.50 & 29.00 & 53.00 & 42.00 & 47.50 & 4.17 & \\
\hline & $\operatorname{LLLT}(p)$ & 17 & 45.76 & 52.00 & 22.00 & 76.00 & 36.00 & 56.00 & 15.04 & \\
\hline \multirow[t]{4}{*}{ Height $(\mathrm{cm})$} & HILT & 18 & 168.67 & 169.50 & 162.00 & 175.00 & 164.00 & 172.00 & 4.26 & 0.7176 \\
\hline & HILT (p) & 17 & $169.4 \mid$ & 172.00 & 158.00 & 181.00 & 159.00 & 175.00 & 7.98 & \\
\hline & LLLT & 16 & 168.88 & 168.00 & 156.00 & 176.00 & 168.00 & 172.00 & 4.57 & \\
\hline & $\operatorname{LLLT}(p)$ & 17 & 169.82 & 170.00 & 164.00 & 177.00 & 168.00 & $17 \mid .00$ & 2.96 & \\
\hline \multirow[t]{4}{*}{ Body weight (kg) } & HILT & 18 & 74.17 & 75.00 & 57.00 & 90.00 & 65.00 & 83.00 & $|1.4|$ & 0.9674 \\
\hline & HILT (p) & 17 & 73.94 & 75.00 & 54.00 & 92.00 & 65.00 & 84.00 & 11.81 & \\
\hline & LLLT & 16 & 75.38 & 75.00 & 59.00 & 92.00 & 62.00 & 90.00 & 12.99 & \\
\hline & $\operatorname{LLLT}(p)$ & 17 & 76.06 & 78.00 & 55.00 & 87.00 & 74.00 & 82.00 & 8.89 & \\
\hline \multirow[t]{4}{*}{ BMI $\left(\mathrm{kg} / \mathrm{m}^{2}\right)$} & HILT & 18 & 25.96 & 26.64 & 21.19 & 31.14 & 22.76 & 28.39 & 3.11 & 0.9782 \\
\hline & HILT (p) & 17 & 25.69 & 25.35 & 21.36 & 30.46 & 22.58 & 28.44 & 3.25 & \\
\hline & LLLT & 16 & 26.42 & 26.25 & 19.05 & 31.89 & 21.97 & 30.42 & 4.31 & \\
\hline & $\operatorname{LLLT}(p)$ & 17 & 26.36 & 27.04 & 18.59 & 28.38 & 26.93 & 27.77 & 2.86 & \\
\hline \multirow[t]{4}{*}{ Duration of disease (months) } & HILT & 18 & 55.89 & 57.00 & 46.00 & 64.00 & 51.00 & 60.00 & 5.97 & 0.9610 \\
\hline & HILT (p) & 17 & 55.41 & 56.00 & 46.00 & 64.00 & 52.00 & 60.00 & 5.96 & \\
\hline & LLLT & 16 & 54.56 & 56.00 & 36.00 & 68.00 & 48.50 & 61.50 & 8.88 & \\
\hline & $\operatorname{LLLT}(p)$ & 17 & 56.47 & 58.00 & 47.00 & 65.00 & 52.00 & 60.00 & 5.68 & \\
\hline
\end{tabular}

Abbreviations: BMI, body mass index; HILT, high-intensity laser therapy group; HILT (p), high-intensity laser therapy placebo group; LLLT, low-level laser therapy group; LLLT (P), low-level laser therapy placebo group; Max, maximum value; Me, median; Min, minimum value; Q25, lower quartile; Q75, upper quartile; SD, standard deviation; $\overline{\mathrm{X}}$, average.

homogenous with respect to initial measurements regarding the assessment of pain intensity, functional status, and range of motion of the joints.

\section{Treatment procedures}

The HILT group consisted of 18 participants (10 men and 8 women) who underwent treatment with high-energy laser therapy (gallium aluminum arsenide; Cyborg Laser; Cosmogamma, Jakarta, Indonesia). Treatment parameters included a constant wave, a contact method, a stable technique, and a spot applicator with a $30 \mathrm{~cm}^{2}$ diffuser above an area of $6 \times 5 \mathrm{~cm}$ on the lower back (guide light of $670 \mathrm{~nm}$, target indicator of $3 \mathrm{~mW}$ red laser pointer, and safety class of I type B), the wavelength of $1,064 \mathrm{~nm}$, the output power of $10 \mathrm{~W}$, the energy density of $60 \mathrm{~J} / \mathrm{cm}^{2}$ (total energy =1,200 J), and the treatment duration of 10 minutes. In all the procedures, the direct dose was measured on a surface of the skin by Mentor MA10 device (ITAM Inc., Warsaw, Poland). In turn, the HILT placebo [HILT (p)] group consisted of 17 participants (9 men and 8 women) who received a series of sham treatments using a high-energy laser. The duration of a single application was 10 minutes.

The LLLT group consisted of 16 participants ( 8 men and 8 women) who underwent low-energy laser therapy (heliumneon; LAS Expert, Physiomed Elektromedizin, Schnaittach,
Germany). Treatment parameters included a constant wave, a dynamic technique, and a $1 \mathrm{~mm}^{2}$ spot applicator of $65 \mathrm{~mW}$ power output, the wavelength of $785 \mathrm{~nm}$, the energy density of $8 \mathrm{~J} / \mathrm{cm}^{2}$, and the treatment duration of 8 minutes (guide light of $670 \mathrm{~nm}$, target indicator of $3 \mathrm{~mW}$ red laser pointer, and safety class of I type B). In all the procedures, the direct dose was measured on a surface of the skin by Mentor MA10 device (ITAM Inc.). In turn, the LLLT placebo [LLLT (p)] group consisted of 17 participants ( 9 men and 8 women) who received a series of sham treatments using a low-energy laser. The duration of a single application was 8 minutes to an area $3 \mathrm{~cm}$ lateral to L5-S1 on the lower back. The applicator was in contact with the skin.

Each participant was blinded in the present study where the applicator emitted a red beam of visible light, but the device did not generate laser beams. The operator was not blinded; however, the investigator performing the outcome measure did not know which group each participant comes from. In addition, all laser treatment sessions were performed by the same qualified physiotherapist. Similarly, all diagnostic measurements were carried out by the same technician.

The study participants from all comparative groups underwent a series of 15 exposures for laser irradiation performed five times a week, once a day, and for three weeks. 


\section{Measurement tools}

The following clinical tests were used to assess the effectiveness of laser therapy in study participants with regard to subjective pain assessment, functional efficiency, and their degree of disability: 1) the visual analogue scale (VAS); 2) the Laitinen Questionnaire Indicators of Pain (LQIP); 3) the Oswestry Disability Index (ODI); 4) the Roland-Morris Disability Questionnaire (RMDQ); 5) Lasegue test (LT); and 6) Schober's test (ST).

All the tests were performed and the measurements were taken before the start of the research project and after its completion. Then, after 1 and 3 months from the end of the treatment sessions (transitional period), the same measurements were repeated as part of observing follow-up results. During the transitional period, the participants were not subjected to any treatment that could interfere with the collected results.

\section{Statistical analysis}

Statistical analysis was performed using the Statistica 12 software (Dell Inc., Round Rock, TX, USA). The arithmetic variables arithmetic means, $\mathrm{SD}$, medians, the range of variation (extreme values), and quartiles were calculated. All studied quantitative variables were estimated using the Shapiro-Wilk test to determine the type of distribution. Comparisons of results between groups were performed using the Kruskal-Wallis nonparametric ANOVA test with multiple comparisons. Intergroup comparisons of the results were performed using the Friedman ANOVA test with multiple comparisons. The level $\alpha=0.05$ was assumed for all analyses. Based on type I error and probability set at 0.05 , with $90 \%$ power, the detection of statistically significant differences between four groups required at least 15 patients in each group (a total of 60 participants).

\section{Results}

After applying verum or placebo laser irradiation, therapeutic progress was observed in all comparative groups in relation to subjective pain sensations measured with the VAS and LQIP. A similar situation was observed in the case of perception of functional efficiency analyzed by the ODI and RMDQ. As a result of the applied treatment, improvement in the mobility of the hip joint in LT and in the lumbosacral spine in ST was also noted. Comparing changes obtained immediately after the completion of physical procedures to the condition before treatment, very favorable remission was found in all four comparative groups (including placebo treatment). It should be pointed out that in the long-term results ( 1 and 3 months after laser therapy), a gradual relapse of symptoms was observed.

The characteristics of the results at particular stages of treatment are shown in Table 2 for the HILT group, in Table 3 for the HILT (p) group, in Table 4 for the LLLT group, and in Table 5 for the LLLT (p) group. The measured parameters were statistically significant in most cases $(p<0.001)$. The change concerning the improvement in the mobility of the right hip joint in LT approached statistical significance $(p=0.081)$ in the HILT group. Similarly, participants treated with LLLT stimulation showed improvement in the mobility of both hip joints, but it was not statistically significant $(p>0.05)$. Table 6 shows the detailed results for the Friedman ANOVA.

The greatest and fastest therapeutic progress was obtained in short-term observation (comparison of results from before the start of the project in relation to the final results achieved immediately after the end of treatment).

Considering intergroup comparisons, it can be stated unequivocally that no statistically significant differences were observed among the four comparative groups. This means that there is no significant difference in the therapeutic effectiveness of laser irradiation with different energy doses and in the use of placebo intervention in appropriate groups. This allows us to state that both high- and low-energy lasers appeared ineffective and showed no therapeutic advantage in the measured parameters in relation to sham interventions in participants with chronic lumbar disc degenerative changes.

There were slightly better results in the HILT group in the subjective perception of pain according to the VAS (immediately after the treatment and a month later in the follow-up observation). However, the LQIP that provides a further and more detailed analysis of pain sensations did not confirm this result. Table 7 shows the detailed results of Kruskal-Wallis ANOVA, which also shows the homogeneity of comparative groups regarding the initial values of the measured parameters.

\section{Discussion}

To our knowledge, our article is currently the only such comprehensive attempt to evaluate the effectiveness of high- and low-energy laser therapies among homogeneous populations of study participants with chronic discogenic LBP (Modic classification). The novelties are the analysis of short- and long-term results and the efforts to estimate the placebo effect of laser irradiation using a single-blind study. Based on a review of the recent literature using top medical databases 
Table 2 Results in HILT group

\begin{tabular}{|c|c|c|c|c|c|c|c|c|}
\hline Time point & Measurement & $\overline{\mathbf{x}}$ & Me & Min & Max & Q25 & Q75 & SD \\
\hline \multirow[t]{7}{*}{ Before } & VAS & 7.22 & 8.00 & 4.00 & 10.00 & 5.00 & 9.00 & 1.96 \\
\hline & LQIP & 9.22 & 8.00 & 5.00 & 15.00 & 7.00 & 11.00 & 3.08 \\
\hline & ODI & 33.61 & 34.00 & 25.00 & 47.00 & 31.00 & 38.00 & 6.57 \\
\hline & RMDQ & | 4.44 & 16.00 & 4.00 & 23.00 & 12.00 & 19.00 & 5.54 \\
\hline & ST & 3.00 & 3.00 & 2.00 & 4.00 & 3.00 & 3.00 & 0.59 \\
\hline & LT (right) & 61.67 & 60.00 & 40.00 & 80.00 & 55.00 & 70.00 & 12.72 \\
\hline & LT (left) & 60.83 & 60.00 & 25.00 & 85.00 & 55.00 & 75.00 & 17.84 \\
\hline \multirow[t]{7}{*}{ After } & VAS & 1.44 & 1.00 & 1.00 & 2.00 & 1.00 & 2.00 & 0.51 \\
\hline & LQIP & 1.83 & 2.00 & 0.00 & 4.00 & 0.00 & 3.00 & 1.58 \\
\hline & ODI & 18.00 & 14.00 & 9.00 & 31.00 & 12.00 & 26.00 & 7.80 \\
\hline & RMDQ & 5.72 & 5.00 & 0.00 & 13.00 & 1.00 & 10.00 & 5.27 \\
\hline & ST & 4.83 & 5.00 & 4.00 & 6.00 & 4.00 & 5.00 & 0.62 \\
\hline & LT (right) & 77.22 & 77.50 & 50.00 & 90.00 & 75.00 & 85.00 & 11.79 \\
\hline & LT (left) & 74.44 & 80.00 & 30.00 & 90.00 & 75.00 & 80.00 & 17.05 \\
\hline \multirow[t]{7}{*}{ I-month follow-up } & VAS & 1.61 & 1.00 & 1.00 & 5.00 & 1.00 & 2.00 & 0.98 \\
\hline & LQIP & 2.28 & 2.00 & 0.00 & 7.00 & 0.00 & 3.00 & 2.30 \\
\hline & ODI & 16.89 & 14.00 & 9.00 & 31.00 & 12.00 & 23.00 & 7.32 \\
\hline & RMDQ & 5.61 & 4.00 & 0.00 & 14.00 & 1.00 & 11.00 & 5.37 \\
\hline & ST & 4.72 & 5.00 & 4.00 & 6.00 & 4.00 & 5.00 & 0.67 \\
\hline & LT (right) & 76.11 & 77.50 & 50.00 & 90.00 & 70.00 & 80.00 & 11.70 \\
\hline & LT (left) & 73.06 & 75.00 & 30.00 & 90.00 & 75.00 & 80.00 & 16.73 \\
\hline \multirow[t]{7}{*}{ 3-month follow-up } & VAS & 1.78 & 1.00 & 1.00 & 5.00 & 1.00 & 2.00 & 1.11 \\
\hline & LQIP & 2.61 & 2.00 & 0.00 & 5.00 & 1.00 & 5.00 & 2.00 \\
\hline & ODI & 17.94 & 15.00 & 11.00 & 31.00 & 12.00 & 26.00 & 7.14 \\
\hline & RMDQ & 4.83 & 3.00 & 0.00 & 14.00 & 1.00 & 11.00 & 5.22 \\
\hline & ST & 4.56 & 4.50 & 3.00 & 6.00 & 4.00 & 5.00 & 0.78 \\
\hline & LT (right) & 74.44 & 75.00 & 50.00 & 90.00 & 70.00 & 80.00 & 11.10 \\
\hline & LT (left) & 71.39 & 75.00 & 30.00 & 90.00 & 75.00 & 80.00 & 17.05 \\
\hline
\end{tabular}

Abbreviations: HILT, high-intensity laser therapy; LQIP, Laitinen Questionnaire Indicators of Pain; LT, Lasegue test; Max, maximum value; Me, median; Min, minimum value; Q25, lower quartile; Q75, upper quartile; ODI, Oswestry Disability Index; RMDQ, Roland-Morris Disability Questionnaire; ST, Schober's test; VAS, visual analogue scale; $\overline{\mathrm{X}}$, average.

such as PubMed, MEDLINE, Scopus, Web of Science Core Collection, and PEDro, no similar publications were found, which highlights the innovation of our research activities. On the other hand, it makes it very difficult to discuss our results in comparison with those obtained by other researchers. It is all the most important because the results achieved in this project proved to be disappointing, and the hopes we had for demonstrating the clinical utility of the tested methods were not realized. Although we used common treatment parameters recommended by other authors and the methodology of laser irradiations was analogical to those in previously published papers, the results we obtained turned out to be surprising as we thought there would be a difference between verum laser and placebo groups.

The experiences of other researchers are also contradictory, which makes it difficult to establish a therapeutic consensus and, consequently, leaves the use of laser therapy in chronic LBP a controversial subject. Therefore, we believe that our results should be verified by other research centers, which will facilitate the access to scientific truth.
The evaluation of the impact of LLLT on the quality of life, pain intensity, and mobility of lumbar spine in patients with chronic LBP has been undertaken by Djavid et al. ${ }^{15}$ The study participants were assigned to three comparative groups. The first group was subjected to laser therapy $(810 \mathrm{~nm}$, $27 \mathrm{~J} / \mathrm{cm}^{2}$ ); in the second group, a standard physiotherapy was conducted, and the third group underwent a sham treatment with LLLT. The following tests and scales were used in the physical examination: ST, VAS, and ODI. Both the short- and long-term results showed no significant changes in all tested parameters.

In a similar study, Gur et a ${ }^{16}$ also compared 75 patients randomly assigned to three comparative groups. In the first group, stabilization training and LLLT treatment were performed (seven selected painful points were irradiated with an energy dose of $1 \mathrm{~J} / \mathrm{cm}^{2}$ ). In the second group, the therapy consisted of laser applications only, and in the third group, only stabilization exercises were performed. In all the groups, the duration of treatment was 4 weeks (Monday to Friday). The ST, VAS, RMDQ, and ODI were used to 
Table 3 Results in HILT sham group

\begin{tabular}{|c|c|c|c|c|c|c|c|c|}
\hline Time point & Measurement & $\overline{\mathbf{x}}$ & Me & Min & $\operatorname{Max}$ & Q25 & Q75 & SD \\
\hline \multirow[t]{7}{*}{ Before } & VAS & 7.59 & 8.00 & 5.00 & 9.00 & 7.00 & 9.00 & 1.42 \\
\hline & LQIP & 8.65 & 9.00 & 4.00 & 13.00 & 6.00 & 12.00 & 3.24 \\
\hline & ODI & 36.82 & 36.00 & 25.00 & 50.00 & 29.00 & 44.00 & 8.95 \\
\hline & RMDQ & $|5.4|$ & 16.00 & 8.00 & 21.00 & 12.00 & 19.00 & 4.17 \\
\hline & ST & 2.71 & 2.50 & 2.00 & 4.00 & 2.00 & 3.00 & 0.64 \\
\hline & LT (right) & 38.24 & 30.00 & 30.00 & 60.00 & 30.00 & 45.00 & 12.11 \\
\hline & LT (left) & 39.71 & 35.00 & 25.00 & 60.00 & 30.00 & 50.00 & 11.38 \\
\hline \multirow[t]{7}{*}{ After } & VAS & 2.53 & 2.00 & 1.00 & 5.00 & 2.00 & 3.00 & 1.28 \\
\hline & LQIP & 2.29 & 2.00 & 0.00 & 4.00 & 2.00 & 3.00 & 1.31 \\
\hline & ODI & 12.53 & 14.00 & 0.00 & 21.00 & 12.00 & 15.00 & 6.51 \\
\hline & RMDQ & 6.71 & 7.00 & 0.00 & 19.00 & 3.00 & 10.00 & 4.97 \\
\hline & ST & 4.24 & 4.00 & 4.00 & 5.00 & 4.00 & 4.00 & 0.44 \\
\hline & LT (right) & 55.29 & 55.00 & 40.00 & 80.00 & 50.00 & 60.00 & 9.92 \\
\hline & LT (left) & 59.41 & 60.00 & 45.00 & 80.00 & 55.00 & 70.00 & 9.82 \\
\hline \multirow[t]{7}{*}{ I-month follow-up } & VAS & 3.12 & 3.00 & 1.00 & 6.00 & 2.00 & 4.00 & 1.45 \\
\hline & LQIP & 2.82 & 3.00 & 0.00 & 6.00 & 2.00 & 4.00 & 1.94 \\
\hline & ODI & 15.82 & 16.00 & 10.00 & 23.00 & 11.00 & 20.00 & 4.54 \\
\hline & RMDQ & 5.29 & 6.00 & 0.00 & 12.00 & 0.00 & 9.00 & 4.50 \\
\hline & ST & 4.12 & 4.00 & 3.00 & 5.00 & 4.00 & 4.00 & 0.60 \\
\hline & LT (right) & 55.59 & 55.00 & 40.00 & 80.00 & 50.00 & 60.00 & 10.14 \\
\hline & LT (left) & 58.24 & 60.00 & 40.00 & 80.00 & 55.00 & 70.00 & 11.45 \\
\hline \multirow[t]{7}{*}{ 3-month follow-up } & VAS & 4.24 & 3.00 & 3.00 & 7.00 & 3.00 & 5.00 & 1.52 \\
\hline & LQIP & 3.82 & 4.00 & 0.00 & 7.00 & 3.00 & 5.00 & 2.13 \\
\hline & ODI & 19.76 & 21.00 & 10.00 & 28.00 & 13.00 & 24.00 & 6.48 \\
\hline & RMDQ & 6.76 & 8.00 & 0.00 & 15.00 & 0.00 & 10.00 & 5.57 \\
\hline & ST & 3.53 & 3.00 & 3.00 & 5.00 & 3.00 & 4.00 & 0.62 \\
\hline & LT (right) & 50.88 & 50.00 & 40.00 & 75.00 & 45.00 & 55.00 & 9.39 \\
\hline & LT (left) & 54.71 & 55.00 & 40.00 & 75.00 & 50.00 & 65.00 & 10.53 \\
\hline
\end{tabular}

Abbreviations: HILT, high-intensity laser therapy; LQIP, Laitinen Questionnaire Indicators of Pain; LT, Lasegue test; Max, maximum value; Me, median; Min, minimum value; Q25, lower quartile; Q75, upper quartile; ODI, Oswestry Disability Index; RMDQ, Roland-Morris Disability Questionnaire; ST, Schober's test; VAS, visual analogue scale; $\overline{\mathrm{X}}$, average.

analyze the patients' condition. Although there was an improvement in the measured parameters, no differences were found between each comparative group. Therefore, no advantage was shown in favor of LLLT compared with standard stabilization training.

Similar results were obtained by De Carvalho et al, ${ }^{17}$ who compared the effectiveness of LLLT and sham interventions with a low-energy laser, as well as light-emitting diode (LED)-type polarized light irradiation. Patients, in addition to the 15 therapeutic applications, performed stretching exercises of the lower limbs. Significant improvement in pain levels, hip joint mobility, and functional efficiency was observed in all the studied groups. Interestingly, the most favorable results were obtained in the group in which LED irradiations were provided. However, due to the lack of intergroup differences between the LLLT and placebo groups, it is likely that the improvement in the examined parameters was due to the physical exercises, which were performed simultaneously.

In contrast, positive results were obtained by Zdrodowska et al, ${ }^{18}$ who undertook a comparison of the effectiveness of
LLLT and magnetotherapy on a group of 120 people with diagnosed discopathy at the L5-S1 segment. The following assessments were used in the physical examination: LT, ST, VAS, and LQIP. The laser therapy included 10 sessions using the contact method with pressure. A laser with a wavelength of $880 \mathrm{~nm}$ was used, and an energy dose of $6 \mathrm{~J} / \mathrm{cm}^{2}$ was applied, which was increased by $1 \mathrm{~J} / \mathrm{cm}^{2}$ with each subsequent exposure until reaching $12 \mathrm{~J} / \mathrm{cm}^{2}$. The results indicated, after LLLT + magnetotherapy application, a reduction in pain and an increase in the mobility of the spine. However, there was no control group, so it is difficult to conclude that the treatment was superior.

A team of Turkish scientists ${ }^{19}$ also showed a positive effect of LLLT of different wavelengths on patients with chronic LBP. All patients underwent therapy including 15 laser irradiation treatments preceded by warming up of the treatment area. In the first group, a laser with a wavelength of $850 \mathrm{~nm}$ was used, and in the second group, a combined wave of 650/785/980 nm was applied. Improvement in spine flexion (ST) and active hip flexion (LT), pain reduction (VAS), and increase in overall physical condition (ODI) were noted 
Table 4 Results in LLLT group

\begin{tabular}{|c|c|c|c|c|c|c|c|c|}
\hline Time point & Measurement & $\overline{\mathbf{x}}$ & $\mathrm{Me}$ & Min & Max & Q25 & Q75 & SD \\
\hline \multirow[t]{7}{*}{ Before } & VAS & 8.50 & 9.00 & 5.00 & 10.00 & 8.00 & 9.50 & 1.55 \\
\hline & LQIP & 7.75 & 8.00 & 4.00 & 12.00 & 6.00 & 9.00 & 2.32 \\
\hline & ODI & 32.38 & 34.00 & 13.00 & 44.00 & 25.50 & 42.00 & 10.34 \\
\hline & RMDQ & 14.44 & 13.50 & 8.00 & 21.00 & 12.00 & 19.00 & 4.30 \\
\hline & ST & 3.19 & 3.00 & 2.00 & 4.00 & 3.00 & 3.50 & 0.54 \\
\hline & LT (right) & 52.81 & 57.50 & 25.00 & 75.00 & 30.00 & 70.00 & 18.71 \\
\hline & LT (left) & 54.69 & 57.50 & 30.00 & 80.00 & 30.00 & 70.00 & 18.84 \\
\hline \multirow[t]{7}{*}{ After } & VAS & 3.63 & 3.50 & 1.00 & 6.00 & 2.50 & 5.00 & 1.45 \\
\hline & LQIP & 4.38 & 4.00 & 2.00 & 9.00 & 3.00 & 5.00 & 2.13 \\
\hline & ODI & 22.69 & 25.50 & 14.00 & 29.00 & 16.00 & 28.00 & 6.22 \\
\hline & RMDQ & 8.50 & 8.00 & 1.00 & 18.00 & 4.50 & 12.00 & 5.29 \\
\hline & ST & 4.31 & 4.50 & 3.00 & 5.00 & 4.00 & 5.00 & 0.79 \\
\hline & LT (right) & 62.50 & 65.00 & 40.00 & 80.00 & 45.00 & 75.00 & 15.06 \\
\hline & LT (left) & 66.25 & 65.00 & 45.00 & 90.00 & 47.50 & 80.00 & 15.86 \\
\hline \multirow[t]{7}{*}{ I-month follow-up } & VAS & 3.75 & 4.00 & 1.00 & 6.00 & 2.50 & 5.00 & 1.57 \\
\hline & LQIP & 4.56 & 4.00 & 1.00 & 10.00 & 2.50 & 5.00 & 2.61 \\
\hline & ODI & 24.38 & 25.50 & 14.00 & 39.00 & 17.00 & 29.00 & 8.29 \\
\hline & RMDQ & 8.44 & 8.00 & 1.00 & 14.00 & 6.00 & 12.50 & 4.59 \\
\hline & ST & 4.13 & 4.00 & 3.00 & 5.00 & 3.00 & 5.00 & 0.89 \\
\hline & LT (right) & 61.25 & 60.00 & 40.00 & 80.00 & 45.00 & 75.00 & 15.22 \\
\hline & LT (left) & 63.13 & 60.00 & 40.00 & 80.00 & 47.50 & 80.00 & 15.59 \\
\hline \multirow[t]{7}{*}{ 3-month follow-up } & VAS & 4.31 & 4.00 & 2.00 & 7.00 & 4.00 & 5.00 & 1.25 \\
\hline & LQIP & 5.38 & 5.00 & 3.00 & 9.00 & 4.00 & 5.00 & 1.89 \\
\hline & ODI & 25.63 & 25.50 & 14.00 & 38.00 & 19.00 & 32.50 & 8.02 \\
\hline & RMDQ & 9.81 & 10.00 & 4.00 & 15.00 & 7.50 & 12.50 & 3.75 \\
\hline & ST & 3.94 & 4.00 & 3.00 & 5.00 & 3.00 & 4.50 & 0.77 \\
\hline & LT (right) & 60.31 & 60.00 & 40.00 & 80.00 & 40.00 & 75.00 & 15.65 \\
\hline & LT (left) & 62.81 & 60.00 & 40.00 & 80.00 & 47.50 & 77.50 & 15.27 \\
\hline
\end{tabular}

Abbreviations: LLLT, low-level laser therapy; LQIP, Laitinen Questionnaire Indicators of Pain; LT, Lasegue test; Max, maximum value; Me, median; Min, minimum value; Q25, lower quartile; Q75, upper quartile; ODI, Oswestry Disability Index; RMDQ, Roland-Morris Disability Questionnaire; ST, Schober's test; VAS, visual analogue scale; $\overline{\mathrm{X}}$, average.

in all patients. However, no differences were found after the application of treatments in the intergroup comparison, with the exception of better mobility (ST and LT) in the group using the combined wavelengths (varied LLLT).

Very few papers analyzing the use of HILT in chronic LBP can be found in the literature because this method is much newer than low-energy laser therapy. Boyraz et $\mathrm{al}^{20}$ compared the interaction of high-energy laser therapy and the use of ultrasound therapy. The study identified three comparative groups of 65 patients with diagnosed L5-S1 discopathy. In the first group $(\mathrm{n}=20)$, HILT procedures were performed, and the Cosmogamma Cyborg Laser (identical to our study) was used with the following treatment parameters: 1,064 nm; $3.8 \mathrm{~W}$, and 1,800 J total dose (in our project: 1,064 nm, $6 \mathrm{~W}$, and 1,800 J total dose). In the second group $(\mathrm{n}=25)$, ultrasound treatment was applied $(3 \mathrm{MHz}, 50 \%, 1.5 \mathrm{~W} / \mathrm{cm}$ for 6 minutes to the lumbar paravertebral area), and in the third group ( $n=20$, the control) isometric trunk exercises were performed. The same training was performed in groups 1 and 2 as a complement to the therapy. The VAS and the ODI were used to analyze the parameters. The researchers found that HILT and ultrasound therapy were relatively efficient therapies for lumbar discopathy, but with comparable effect to standard physical exercises.

The aim of the study by Alayat et $\mathrm{al}^{21}$ also provided verification of the legitimacy of using high-energy laser therapy in chronic LBP. In total, 72 patients were randomly assigned to three comparative groups. Group 1 was exposed to laser irradiation $\left(1,064 \mathrm{~nm}, 50 \mathrm{~J} / \mathrm{cm}^{2}\right)$ together with trunk stabilization exercises; in group 2, sham HILT and stabilization exercises were used; and in group 3, only high-energy laser sessions were performed. The therapeutic program in all groups lasted for 4 weeks. In addition, measurements of the lumbar spine flexion were taken; however, in contrast to our design, a back rangeof-motion device, which involves a patented inclinometer, was used. The intergroup comparison showed no significant differences between the placebo group (group 2) and the HILT group (group 3), as well as the advantage of group 1 (combining HILT + exercises) over others. Interestingly, similar to our study, significant improvement in tested parameters within groups was noted in early results, and relapse occurred 2 months after the end of the treatment procedure. 
Table 5 Results in LLLT sham group

\begin{tabular}{|c|c|c|c|c|c|c|c|c|}
\hline Time point & Measurement & $\overline{\mathbf{x}}$ & Me & Min & Max & Q25 & Q75 & SD \\
\hline \multirow[t]{7}{*}{ Before } & VAS & 7.18 & 7.00 & 5.00 & 10.00 & 6.00 & 8.00 & 1.67 \\
\hline & LQIP & 6.94 & 6.00 & 4.00 & 12.00 & 5.00 & 9.00 & 2.66 \\
\hline & ODI & 32.24 & 29.00 & 23.00 & 54.00 & 28.00 & 33.00 & 8.99 \\
\hline & RMDQ & |3.7| & 13.00 & 9.00 & 22.00 & 10.00 & 16.00 & 4.19 \\
\hline & ST & 4.12 & 4.00 & 3.00 & 5.00 & 3.00 & 5.00 & 0.86 \\
\hline & LT (right) & 58.53 & 65.00 & 30.00 & 75.00 & 50.00 & 65.00 & 13.32 \\
\hline & LT (left) & 56.18 & 55.00 & 35.00 & 75.00 & 50.00 & 65.00 & 13.17 \\
\hline \multirow[t]{7}{*}{ After } & VAS & 2.76 & 3.00 & 1.00 & 6.00 & 2.00 & 3.00 & 1.25 \\
\hline & LQIP & 3.06 & 4.00 & 0.00 & 7.00 & 2.00 & 4.00 & 2.14 \\
\hline & ODI & 19.76 & 20.00 & 10.00 & 35.00 & 16.00 & 25.00 & 7.00 \\
\hline & RMDQ & $5.4 I$ & 3.00 & 1.00 & 16.00 & 2.00 & 9.00 & 4.77 \\
\hline & ST & 5.06 & 5.00 & 4.00 & 6.00 & 5.00 & 6.00 & 0.75 \\
\hline & LT (right) & 69.71 & 70.00 & 45.00 & 85.00 & 65.00 & 75.00 & 10.82 \\
\hline & LT (left) & 66.76 & 70.00 & 45.00 & 85.00 & 65.00 & 75.00 & 12.37 \\
\hline \multirow[t]{7}{*}{ I-month follow-up } & VAS & 2.82 & 3.00 & 1.00 & 7.00 & 2.00 & 4.00 & 1.63 \\
\hline & LQIP & 3.06 & 3.00 & 0.00 & 7.00 & 2.00 & 4.00 & 2.19 \\
\hline & ODI & 18.47 & 19.00 & 10.00 & 32.00 & 14.00 & 21.00 & 7.10 \\
\hline & RMDQ & 4.35 & 2.00 & 0.00 & 17.00 & 1.00 & 9.00 & 4.85 \\
\hline & ST & 4.88 & 5.00 & 4.00 & 6.00 & 4.00 & 5.00 & 0.78 \\
\hline & LT (right) & 69.41 & 70.00 & 45.00 & 80.00 & 65.00 & 75.00 & 10.44 \\
\hline & LT (left) & 65.29 & 65.00 & 45.00 & 80.00 & 65.00 & 75.00 & 11.79 \\
\hline \multirow{7}{*}{ 3-month follow-up } & VAS & 2.88 & 3.00 & 1.00 & 8.00 & 2.00 & 3.00 & 1.69 \\
\hline & LQIP & 3.24 & 3.00 & 0.00 & 8.00 & 2.00 & 4.00 & 2.33 \\
\hline & ODI & 19.12 & 17.00 & 10.00 & 36.00 & 15.00 & 23.00 & 7.69 \\
\hline & RMDQ & 5.00 & 2.00 & 0.00 & 13.00 & 1.00 & 10.00 & 4.85 \\
\hline & ST & 4.59 & 5.00 & 3.00 & 6.00 & 4.00 & 5.00 & 0.80 \\
\hline & LT (right) & 68.24 & 70.00 & 45.00 & 80.00 & 65.00 & 75.00 & 10.45 \\
\hline & LT (left) & 64.71 & 65.00 & 45.00 & 80.00 & 60.00 & 75.00 & 11.52 \\
\hline
\end{tabular}

Abbreviations: LLLT, low-level laser therapy; LQIP, Laitinen Questionnaire Indicators of Pain; LT, Lasegue test; Max, maximum value; Me, median; Min, minimum value; Q25, lower quartile; Q75, upper quartile; ODI, Oswestry Disability Index; RMDQ, Roland-Morris Disability Questionnaire; ST, Schober's test; VAS, visual analogue scale; $\bar{X}$, average.

Positive results of high-energy laser therapy were reported by Fiore et al..$^{22}$ The effectiveness of HILT and ultrasound therapy (frequency $=1 \mathrm{MHz}$, dose $=2 \mathrm{~W} / \mathrm{cm}^{2}$, duty cycle $=100 \%$ ) was studied among 30 patients with back pain who were randomly assigned to two comparison groups. Laser irradiation treatments were performed in accordance with $1,064 \mathrm{~nm}$ and 1,200 $\mathrm{J}$ of the total dosage - the same as in our study. The physical examination included pain assessment with the VAS and the quality of life with the ODI before and after the 3-week therapy. Significant improvement in the examined parameters was noted in both groups. In addition, the HILT group achieved a greater reduction of symptoms than the group treated with ultrasound $(p<0.005)$.

Choi et $\mathrm{a}^{23}$ evaluated the effectiveness of high-energy laser therapy in patients with chronic LBP. Twenty patients were assigned to two comparative groups. In the first group, patients underwent HILT procedures and conventional therapy including (thermal compresses, ultrasound therapy, and electrotherapy with interference currents). In the second group, the subjects were treated only with conventional physiotherapy (excluding laser therapy). The therapy included treatments conducted three times a week for a period of 4 weeks. The VAS and ODI were used as measurement tools before and after treatment. After the end of the treatment sessions, there was an improvement in the examined indicators in both the groups, and the intergroup comparison showed that patients who underwent HILT irradiation achieved better results compared with the others ( $p<0.01$ for VAS and $p<0.05$ for ODI).

A team of Italian researchers ${ }^{24}$ was also interested in high-energy laser therapy in LBP. A comparison of the effects of different laser wavelengths in two comparative groups (group 1 with simultaneous application of 650 and $810 \mathrm{~nm}$ and group 2 with simultaneous application of 810 , 980 , and 1,064 $\mathrm{nm}$ ) was done with constant parameters of the applied dose $\left(5 \mathrm{~W}, 50 \mathrm{~J} / \mathrm{cm}^{2}\right)$ after a series of treatment sessions including 10 daily treatments. The VAS, ODI, and RMDQ were used for the analysis and measured before treatment ( $\mathrm{T}$ before); at the end of the treatment session (T after); and 1 month (T1), 2 months (T2), and 4 months of 
Table 6 Comparison within all groups (short-term results with follow-ups)

\begin{tabular}{|c|c|c|c|}
\hline Measurement & Group & F-value & $p$-value \\
\hline VAS & HILT & 90.30 & 0.0000 \\
\hline LQIP & HILT & 41.60 & 0.0000 \\
\hline ODI & HILT & 22.18 & 0.0000 \\
\hline RMDQ & HILT & 12.99 & 0.0000 \\
\hline ST & HILT & 29.59 & 0.0000 \\
\hline LT (right) & HILT & 6.69 & 0.0000 \\
\hline LT (left) & HILT & 2.34 & 0.0810 \\
\hline VAS & HILT (p) & 43.04 & 0.0000 \\
\hline LQIP & HILT (p) & 27.93 & 0.0000 \\
\hline ODI & HILT (p) & 42.88 & 0.0000 \\
\hline RMDQ & HILT (p) & 15.80 & 0.0000 \\
\hline ST & HILT (p) & 24.65 & 0.0000 \\
\hline LT (right) & HILT (p) & 10.32 & 0.0000 \\
\hline LT (left) & HILT (p) & 12.02 & 0.0000 \\
\hline VAS & LLLT & 40.36 & 0.0000 \\
\hline LQIP & LLLT & 7.56 & 0.0000 \\
\hline ODI & LLLT & 4.14 & 0.0000 \\
\hline RMDQ & LLLT & 6.29 & 0.0000 \\
\hline ST & LLLT & 6.75 & 0.0000 \\
\hline LT (right) & LLLT & 1.16 & 0.3336 \\
\hline LT (left) & LLLT & 1.44 & 0.2397 \\
\hline VAS & $\operatorname{LLLT}(p)$ & 32.62 & 0.0000 \\
\hline LQIP & LLLT (p) & 11.39 & 0.0000 \\
\hline ODI & $\operatorname{LLLT}(p)$ & $|2.3|$ & 0.0000 \\
\hline RMDQ & $\operatorname{LLLT}(p)$ & 15.17 & 0.0000 \\
\hline ST & LLLT (p) & 4.54 & 0.0000 \\
\hline LT (right) & $\operatorname{LLLT}(p)$ & 3.77 & 0.0000 \\
\hline LT (left) & $\operatorname{LLLT}(p)$ & 2.60 & 0.0595 \\
\hline
\end{tabular}

Note: Statistically significant values shown in bold.

Abbreviations: HILT, high-intensity laser therapy group; HILT (p), high-intensity laser therapy placebo group; LLLT, low-level laser therapy group; LLLT (p), lowlevel laser therapy placebo group; LQIP, Laitinen Questionnaire Indicators of Pain; LT, Lasegue test; ODI, Oswestry Disability Index; RMDQ, Roland-Morris Disability Questionnaire; ST, Schober's test; VAS, visual analogue scale.

follow-ups (T4). In each group, authors verified a statistically significant improvement over time and a relationship between the time and treatment $(p<0.01)$. At T1 for all wavelengths, they found a statistically significant improvement in the three scores $(p<0.01)$, which was maintained up to T4. All the wavelengths analyzed proved to be efficacious for LBP.

In our study, the placebo effect appeared to be very meaningful. After sham irradiations, we reported a significant improvement in all measured parameters. In a systematic review, Puhl et $\mathrm{al}^{25}$ presented the role of placebo in laser therapy. All included clinical trials ${ }^{26-28}$ using sham laser as a placebo intervention included subjects whose LBP could be considered chronic. These studies primarily used subjective continuous outcome measures for both pain (eg, VAS, McGill Pain Questionnaire, and Modified Brief Pain Inventory) and disability (eg, RMDQ and ODI). Two studies found no improvement of pain or disability from baseline after 4 weeks of sham laser intervention. However, the use of
Table 7 Intergroup comparisons (short-term results with follow-ups)

\begin{tabular}{|c|c|c|c|}
\hline Measurement & Time point & F-value & $p$-value \\
\hline VAS & Before & 2.23 & 0.0931 \\
\hline LQIP & Before & 2.13 & 0.1047 \\
\hline ODI & Before & 1.00 & 0.3991 \\
\hline RMDQ & Before & 0.39 & 0.7594 \\
\hline ST & Before & 1.34 & 0.2889 \\
\hline LT (right) & Before & 1.56 & 0.2045 \\
\hline LT (left) & Before & 1.35 & 0.2467 \\
\hline VAS & After & 4.57 & 0.0234 \\
\hline LQIP & After & 2.02 & 0.1788 \\
\hline ODI & After & 1.24 & 0.3550 \\
\hline RMDQ & After & 1.24 & 0.3043 \\
\hline ST & After & 1.56 & 0.1334 \\
\hline LT (right) & After & 1.78 & 0.2334 \\
\hline LT (left) & After & 1.76 & 0.2780 \\
\hline VAS & I month (follow-up) & 3.32 & 0.0345 \\
\hline LQIP & I month (follow-up) & 1.46 & 0.2445 \\
\hline ODI & I month (follow-up) & 1.78 & 0.4001 \\
\hline RMDQ & I month (follow-up) & 1.03 & 0.1031 \\
\hline ST & I month (follow-up) & 2.14 & $0.4|2|$ \\
\hline LT (right) & I month (follow-up) & I.II & 0.3556 \\
\hline LT (left) & I month (follow-up) & 1.23 & 0.3103 \\
\hline VAS & 3 months (follow-up) & 1.22 & 0.0878 \\
\hline LQIP & 3 months (follow-up) & 2.78 & 0.3291 \\
\hline ODI & 3 months (follow-up) & 1.12 & 0.2357 \\
\hline RMDQ & 3 months (follow-up) & 1.56 & 0.5678 \\
\hline ST & 3 months (follow-up) & 0.56 & 0.8321 \\
\hline LT (right) & 3 months (follow-up) & 0.23 & 0.7634 \\
\hline LT (left) & 3 months (follow-up) & 0.35 & 0.8223 \\
\hline
\end{tabular}

Note: Statistically significant values shown in bold.

Abbreviations: LQIP, Laitinen Questionnaire Indicators of Pain; LT, Lasegue test; ODI, Oswestry Disability Index; RMDQ, Roland-Morris Disability Questionnaire; ST, Schober's test; VAS, visual analogue scale.

overall averages for reporting data in these studies may have concealed any minor benefits incurred by a small subgroup of their subject populations. One study found a clinically meaningful improvement of pain in $69.7 \%$ of subjects in the placebo group following 2 weeks of sham laser intervention. It seems to be another interesting aspect of LBP management, which should be examined by researchers in further studies.

\section{Study limitations}

Significant contradictions in the literature reports make this subject intriguing in terms of science but significantly hinder daily clinical practice and do not give therapists a clear answer on whether to use laser therapy. Even if the answer is potentially affirmative, it is not explained what range of wavelengths or what treatment parameters should be used clearly in the treatment of discogenic changes. Limitations in the literature and in our own study include the lack of 
objective measurement tools (ie, tensometric platform, isokinetic strength dynamometer, surface electromyography, or goniometric pendulum test). ${ }^{29,30}$ Drawing our own results, subjective tests and questionnaires (despite their referentiality and high popularity) need to be combined with more objective outcome measures, and study sample sizes need to be increased. Our team plans to continue research on laser therapy with a randomized, placebo-controlled, double-blind study in future.

\section{Conclusion}

The high- and low-energy laser therapy methods used in the present study are ineffective in relation to patients with lumbar disc degenerative changes in both the short- and long-term perspectives and do not show a significant advantage over the placebo effect. Treatments at this dosage with laser irradiation do not significantly reduce the pain, do not increase the mobility of the lower spine, and do not improve general functional status. It is unknown whether the laser is ineffective or whether the outcome measures need to be more sensitive. Further studies are still needed to assess the clinical effectiveness of laser therapy, and our results should be verified by other research centers.

\section{Availability of data and materials}

The authors confirm that all data underlying the findings described in this manuscript are fully available to all interested researchers upon request.

\section{Acknowledgment}

This study was conducted under a research project funded by the Ministry of Science and Higher Education in Poland as a part of a statutory grant of the Wroclaw Medical University for maintaining research potential (No ST.E020.17.050).

\section{Author contributions}

All the authors of this manuscript met the authorship criteria according to the latest guidelines of the International Committee of Medical Journal Editors and approved the manuscript being submitted and published. All authors substantially contributed to the conception or design of the work, or the acquisition, analysis, or interpretation of data for the work; drafted the work or revised it critically for important intellectual content; approved the final version to be published; and agreed to be accountable for all aspects of the work in ensuring that questions related to the accuracy or integrity of any part of the work were appropriately investigated and resolved.

\section{Disclosure}

The authors report no conflicts of interest in this work.

\section{References}

1. Chow RT, Armati PJ. Photobiomodulation: implications for anesthesia and pain relief. Photomed Laser Surg. 2016;34(12):599-609.

2. Alessi Pissulin CN, Henrique Fernandes AA, Sanchez Orellana AM, Rossi E, Silva RC, Michelin Matheus SM. Low-level laser therapy (LLLT) accelerates the sternomastoid muscle regeneration process after myonecrosis due to bupivacaine. J Photochem Photobiol B. 2017; 168:30-39.

3. Issa JPM, Trawitzki BF, Ervolino E, Macedo AP, Lilge L. Low-intensity laser therapy efficacy evaluation in FVB mice subjected to acute and chronic arthritis. Lasers Med Sci. 2017;32(6):1269-1277.

4. Micheli L, Di Cesare Mannelli L, Lucarini E, et al. Photobiomodulation therapy by NIR laser in persistent pain: an analytical study in the rat. Lasers Med Sci. 2017;32(8):1835-1846.

5. Tomazoni SS, Frigo L, Dos Reis Ferreira TC, et al. Effects of photobiomodulation therapy and topical non-steroidal anti-inflammatory drug on skeletal muscle injury induced by contusion in rats-part 2: biochemical aspects. Lasers Med Sci. 2017;32(8):1879-1887.

6. Ferraresi C, Bertucci D, Schiavinato J, et al. Effects of light-emitting diode therapy on muscle hypertrophy, gene expression, performance, damage, and delayed-onset muscle soreness: case-control study with a pair of identical twins. Am J Phys Med Rehabil. 2016;95(10): 746-757.

7. S GN, Kamal W, George J, Manssor E. Radiological and biochemical effects (CTX-II, MMP-3, 8, and 13) of low-level laser therapy (LLLT) in chronic osteoarthritis in Al-Kharj, Saudi Arabia. Lasers Med Sci. 2017;32(2):297-303.

8. Alayat MSM, Abdel-Kafy EM, Elsoudany AM, Helal OF, Alshehri MA. Efficacy of high intensity laser therapy in the treatment of male with osteopenia or osteoporosis: a randomized placebo-controlled trial. J Phys Ther Sci. 2017;29(9):1675-1679.

9. Alayat MS, Elsoudany AM, Ali ME. Efficacy of multiwave locked system laser on pain and function in patients with chronic neck pain: a randomized placebo-controlled trial. Photomed Laser Surg. 2017;35(8): 450-455.

10. Vitse J, Bekara F, Byun S, Herlin C, Teot L. A double-blind, placebocontrolled randomized evaluation of the effect of low-level laser therapy on venous leg ulcers. Int J Low Extrem Wounds. 2017;16(1):29-35.

11. Wylde V, Dennis J, Beswick AD, et al. Systematic review of management of chronic pain after surgery. Br J Surg. 2017;104(10):1293-1306.

12. Law D, McDonough S, Bleakley C, Baxter GD, Tumilty S. Laser acupuncture for treating musculoskeletal pain: a systematic review with meta-analysis. J Acupunct Meridian Stud. 2015;8(1):2-16.

13. Yousefi-Nooraie R, Schonstein E, Heidari K, et al. Low level laser therapy for nonspecific low-back pain. Cochrane Database Syst Rev. 2008;(2): CD005107.

14. Huang Z, Ma J, Chen J, Shen B, Pei F, Kraus VB. The effectiveness of low-level laser therapy for nonspecific chronic low back pain: a systematic review and meta-analysis. Arthritis Res Ther. 2015;17:360.

15. Djavid GE, Mehrdad R, Ghasemi M, Hasan-Zadeh H, SotoodehManesh A, Pouryaghoub G. In chronic low back pain, low level laser therapy combined with exercise is more beneficial than exercise alone in the long term: a randomised trial. Aust J Physiother. 2007;53(3): $155-160$.

16. Gur A, Karakoc M, Cevik R, Nas K, Sarac AJ, Karakoc M. Efficacy of low power laser therapy and exercise on pain and functions in chronic low back pain. Lasers Surg Med. 2003;32(3):233-238.

17. de Carvalho ME, de Carvalho RM Jr, Marques AP, et al. Low intensity laser and LED therapies associated with lateral decubitus position and flexion exercises of the lower limbs in patients with lumbar disk herniation: clinical randomized trial. Lasers Med Sci. 2016;31(7): 1455-1463. 
18. Zdrodowska B, Leszczyńska-Filus M, Leszczyński R, Błaszczyk J. Porównanie wpływu laseroterapii i magnetoterapii na poziom bólu oraz zakres ruchomości kręgosłupa osób z chorobą zwyrodnieniową dolnego odcinka kręgosłupa [Comparison of the effect of laser and magnetic therapy for pain level and the range of motion of the spine of people with osteoarthritis lower back]. Pol Merkur Lekarski. 2015;38(223):26-31. Polish.

19. Koldaş Doğan Ş, Ay S, Evcik D. The effects of two different low level laser therapies in the treatment of patients with chronic low back pain: a double-blinded randomized clinical trial. J Back Musculoskelet Rehabil. 2017;30(2):235-240.

20. Boyraz I, Yildiz A, Koc B, Sarman H. Comparison of high-intensity laser therapy and ultrasound treatment in the patients with lumbar discopathy. Biomed Res Int. 2015;2015:304328.

21. Alayat MS, Atya AM, Ali MM, Shosha TM. Long-term effect of highintensity laser therapy in the treatment of patients with chronic low back pain: a randomized blinded placebo-controlled trial. Lasers Med Sci. 2014;29(3):1065-1073.

22. Fiore P, Panza F, Cassatella G, et al. Short-term effects of high-intensity laser therapy versus ultrasound therapy in the treatment of low back pain: a randomized controlled trial. Eur J Phys Rehabil Med. 2011;47(3): 367-373.

23. Choi HW, Lee J, Lee S, et al. Effects of high intensity laser therapy on pain and function of patients with chronic back pain. J Phys Ther Sci. 2017;29(6):1079-1081.
24. Notarnicola A, Maccagnano G, Tafuri S, Gallone MF, Moretti L, Moretti B. High level laser therapy for the treatment of lower back pain: clinical efficacy and comparison of different wavelengths. J Biol Regul Homeost Agents. 2016;30(4):1157-1164.

25. Puhl AA, Reinhart CJ, Rok EH, Injeyan S. An examination of the observed placebo effect associated with the treatment of low back pain - a systematic review. Pain Res Manag. 2011;16(1):45-52.

26. Preyde M. Effectiveness of massage therapy for subacute low-back pain: A randomized controlled trial. CMAJ. 2000;162(13):1815-1820.

27. Basford JR, Shefield CG, Harmsen WS. Laser therapy: a randomized, controlled trial of the effects of low-intensity Nd:YAG laser irradiation on musculoskeletal back pain. Arch Phys Med Rehabil. 1999;80(6):647-652.

28. Soriano F, Rios R. Gallium arsenide laser treatment of chronic low back pain: a prospective, randomized and double blind study. Laser Ther. 1998; 10:175-180.

29. Rajfur J, Pasternok M, Rajfur K, et al. Efficacy of selected electrical therapies on chronic low back pain: a comparative clinical pilot study. Med Sci Monit. 2017;23:85-100.

30. Taradaj J, Halski T, Kucharzewski M, et al. The effect of neuromuscular electrical stimulation on quadriceps strength and knee function in professional soccer players: return to sport after ACL reconstruction. Biomed Res Int. 2013;2013:802534.
Clinical Interventions in Aging

\section{Publish your work in this journal}

Clinical Interventions in Aging is an international, peer-reviewed journal focusing on evidence-based reports on the value or lack thereof of treatments intended to prevent or delay the onset of maladaptive correlates of aging in human beings. This journal is indexed on PubMed Central, MedLine,

\section{Dovepress}

CAS, Scopus and the Elsevier Bibliographic databases. The manuscript management system is completely online and includes a very quick and fair peer-review system, which is all easy to use. Visit http://www.dovepress. com/testimonials.php to read real quotes from published authors. 